\title{
THERMODYNAMIC EVALUATION OF ENERGY RECOVERY SYSTEM FOR HEAVY DUTY DIESEL ENGINE BY USING ORGANIC RANKINE CYCLE
}

\author{
Tolga YASA * \\ Deparment of Mechanical Engineering, Faculty of Engineering Anadolu University, Eskişehir, Turkey
}

\begin{abstract}
The internal combustion engine is used daily for transportation and energy production beside their low thermal efficiency level. Most of the thermal energy in such engines is wasted. Therefore, energy recovery is crucial in order to enhance their performance and reduce their environmental impact. The present paper discusses the energy recovery potential of a diesel engine cooling system by using organic Rankine cycle (ORC) based system. An heavy-duty diesel engine that has a maximum brake power rating of about $345 \mathrm{~kW}$ is selected for the investigation. Around eighty different type organic fluids are analyzed to find most suitable working fluid. Operability margin of each fluid as a function of the cooling system pressure is identified based on fix evaporator and condensation conditions. The mass flow rates required for each ORC system are computed together with the cycle thermal efficiencies. The results show that such ORC system is capable of recovering up to $13.6 \%$ of the engine waste heat which corresponds to a power recovery of about $24 \mathrm{~kW}$ and enhances the diesel engine brake efficiency by $2.4 \%$.
\end{abstract}

Keywords: Organic Rankine cycle, Internal combustion engine, Heat recovery, Sustainable energy.

\section{INTRODUCTION}

Internal combustion engines (ICE) are widely used in daily life including transportation, energy production, marine applications, etc. but it mainly dominates the transportation field. $92.4 \%$ of all passenger transportation traffic is operated by cars, buses and coaches in Europe [1]. In addition to the passenger transportation, ICE are the main source of power for the freight operations. Based on the recent Eurostat data from 2014, the freight transport by roads covers almost 75\% of all freight traffic in Europe [2] which is carried out by trucks. Although the usage of ICE is so widespread, they are considered to be rather inefficient. Their averaged brake efficiency is limited to $45 \%$ and $41 \%$ of the fuel energy for heavy duty and low duty diesel engines, respectively. The rest of the energy is wasted by engine cooling and exhaust gases [3]. Hence, there is still some room for performance enhancement of ICE by integrating energy recovery systems. In the last decades, a lot of effort is put to increase the performance by using exhaust gases. As a result of that, the turbocharging unit is introduced successfully to benefit from the waste exhaust heat. On the other hand, a significant amount of fuel energy is dissipated by the engine cooling system which transfers the excessive heat from the engine block to the air. For decades, the engine cooling system has remained unchanged despite all developments in the engine technology.

Organic Rankine cycle (ORC) has recently become popular for the energy recovery systems due to the ease of application to low temperature energy sources [4]. Such systems operate similar to the classical Rankine cycle. Yet, as the working fluid, an organic component like refrigerant fluids is preferred instead of water. Those organic fluids have lower boiling temperatures so they make the usage of Rankine cycle feasible for the low temperature energy sources. The ORC systems take attention for ICE applications to benefit from wasted exhaust or cooling energy.

Selection of proper operating condition has significant effect on the ORC performance. Yamamoto et al. [5] compare the work output of an ORC system using HCFC-123 as a working fluid for various 
turbine inlet temperatures and turbine pressure ratios. The best operation conditions are obtained when the fluid temperature is slightly above the saturation limit. Further increase of vapor temperature actually reduces the system performance. Chen et al. are acquired to similar conclusion when benzene is used [8]. Yang et al. investigate the best conditions of an ORC system for diesel engine that uses the exhaust gases as the heat resource [6]. They focus on the optimum pressure and temperature values of the ORC system giving maximum net power output at various engine operations. Based on their research, the optimum operation pressure is significantly affected by the engine conditions while the optimum value for the evaporator temperature and the condensation temperature remain unaltered. The effect of the turbine inlet conditions of an ORC system is analyzed for subcritical and supercritical conditions for a biogas fueled combine engine where R245fa is considered as the working fluid [7]. It is found that the thermal efficiency of the system decreases by increasing the turbine inlet temperature at the turbine inlet pressures below 12 bar. When the turbine inlet pressure is set to a value beyond 12 bar, thermal efficiency increases proportional to the turbine inlet temperature.

The performance of ORC-based units and the size of components highly depend on the working fluid types. Therefore, the selection of the correct fluid for a specific application is one of the oldest topic in the research area. One of the early studies focusing on the fluid types is provided by Maizza and Maizza [9] where the performance of number of fluids is analyzed in a general manner. Wang et al. [10] and Tian et al. [11] investigate the optimum working fluid that is suitable for the exhaust heat recovery. Their results show that R245fa, R245ca, R141b and R123 are the best candidates. Beside from the pure fluids, the performance of fluid mixtures is investigated to use it in the ORC system for the internal combustion engine energy recovery [12]. In the scope of the study, the thermal performance of pure R245fa providing the maximum net power output is compared to the one obtained with the R245fahydrocarbon mixtures. An addition of about 5\% benzene to the R245fa increases the thermal efficiency of the system by $11.5 \%$ compared to the one of pure fluid.

The application of ORC system to the internal combustion engines is gaining popularity during the last decade. Wang et al. [13] report the thermo-economic benefit of ORC system for exhaust heat recovery. Their analysis shows that such system is capable of improving the thermal efficiency between 2-5\% depending on the operation pressure. Zhao et al. have recently studied the feasibility of using ORC in the exhaust system of diesel engine [14]. They installed an evaporator at the exhaust assembly of the engine with a power rating of $258 \mathrm{~kW}$ and select R245fa as the working fluid. The ORC system operated at 9 bar. Based on their study, the thermal efficiency of the diesel engine was improved by $0.64 \%$. Badescu et al. [15] also studied an ORC system for the internal combustion engines that is used for electric production. The exhaust gases are the main source of the energy for the heat recovery system. Based on isentropic consideration, the designed system provides a thermal efficiency of up to $16.6 \%$. Yu et al. [16] combine the exhaust heat loss together with the engine cooling system for their ORC system where R245fa is employed as the working fluid. They state that $75 \%$ and $9.5 \%$ of exhaust gas waste heat and the engine cooling heat is recovered by their ORC design.

The current investigation aims to analyses a simple ORC cycle which can recover some waste energy of a heavy-duty diesel engine. The heat dissipated by the engine cooling system is the main energy source for the ORC. The evaporator outlet temperature and condenser temperature is limited for the analysis keeping mind the real operation conditions of the diesel engine. The turbine operation parameters like the expansion ratio and efficiency are fixed in order to have comparable results. A wide range of fluid types are investigated to determine the range of operating pressure. The results show that RC318, R236 and R114 are the most suitable fluids for such system when the thermal efficiency is the criteria. The thermal efficiencies of above $10 \%$ are achievable depending on the operating pressure when those fluids are used, which enhance the diesel engine performance by nearly $2.5 \%$. 


\section{INTERNAL COMBUSTION ENGINE ANALYSIS}

The internal combustion engines are one of the main power plant used in the logistic needs. About $76 \%$ of the total good transportation operations are carried out by the land transportation in Turkey [17]. The total amount of 29300 trucks is employed to perform those operations [17]. On the other hand, the trucks operate at constant conditions (transport velocity of $90-100 \mathrm{~km} / \mathrm{h}$ ) for longer duration compared to the personal vehicles which results in more stable engine operation. The data of engines are collected from the specification sheets of world top truck makers and listed in Table 1.

Table 1. Engine Parameters of trucks

\begin{tabular}{ccccc}
\hline Manufacturer & Model & Engine & $\begin{array}{c}\text { Max. Brake } \\
\text { Power [kW] }\end{array}$ & $\begin{array}{c}\text { Cruise Brake } \\
\text { Power [kW] }\end{array}$ \\
\hline Ford & $1848 \mathrm{~T}$ & Ecotorq 12.7 L & 358.1 & 265.2 \\
Renault & T440 & DTI 13 12.8 L & 358.1 & 254.7 \\
MAN & TGX & D2676 12.4 L & 357.8 & 256.2 \\
Volvo & FH & D13K460 12.8 L & 343.8 & 244.0 \\
Mercedes & Actros & OM471 12.8 L & 334.8 & 256.7 \\
DAF & XF & MX-13 12.9 L & 344.4 & 244.0 \\
\hline & & Average & $\mathbf{3 4 9 . 5}$ & $\mathbf{2 5 3 . 5}$ \\
\hline
\end{tabular}

The engine brake power (BHP) is defined as the power which is directly measured from the engine crack shaft. Thus, it only reflects the engine useful mechanical power. However the total energy produced by the combustion is much higher than the BHP since part of the combustion energy is wasted by the engine cooling and exhaust gases. For a diesel engine, typical thermal efficiency is in the range of $29 \%$ and $42 \%$ while the heat wasted by engine cooling varies from $15 \%$ to $35 \%$, and the exhaust loss is in between $25 \%$ and $45 \%$ of the total combustion energy [18-20]. Hence, in the current study it is assumed that $36 \%$ $(253 \mathrm{~kW})$ of the combustion energy is converted to the brake power while $25 \%$ (176 kW) and $36 \%$ $(253 \mathrm{~kW})$ are wasted by the engine cooling and the exhaust gases respectively.

\section{MODEL DEVELOPMENT AND FORMULATION}

The simple ORC system consists of four components namely, an evaporator and condenser for heat exchange, a turbine for mechanical power production and a pump to recirculate the working fluid. In a conventional engine, the cooling fluid (mixture of water and glycol) is passed around the cylinder to remove the excessive heat away. Hence, the engine block itself acts as a heat exchanger. Considering that, the cavity used for conventional cooling system in an ICE is assumed as the evaporator of the ORC. Since the mass flow rate of the organic fluid is different than the one of the conventional water mixture, the redesign of the cooling cavity is required for the application. Similarly, the radiator and recirculation pump of the conventional cooling system can also be converted and employed to the ORC system as the condenser and pump units, respectively. Therefore, such heat recovery unit requires only a turbine module in addition to the conventional cooling system. Based on these assumptions, the schematic of the system is depicted in Figure 1. 


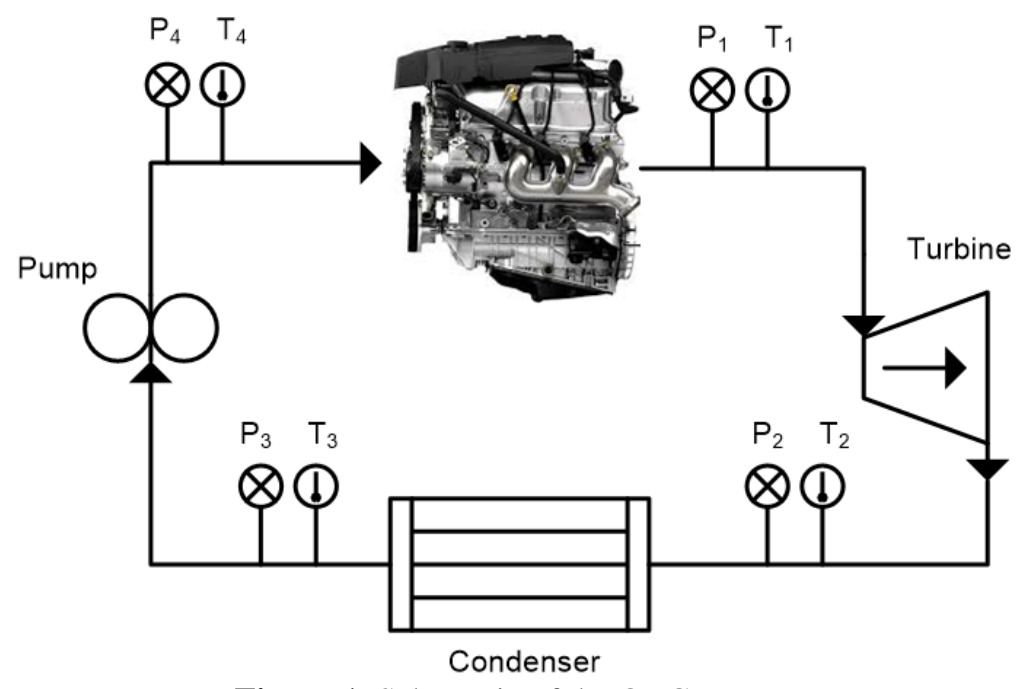

Figure 1. Schematic of the ORC system

The fluid conditions must be specified at a certain location when the cycle performance is investigated. Then, the operating conditions at other locations are computed based on the component properties. For the current study, the engine outlet is selected as the initial location to define the fluid conditions. The flow properties are specified by using temperature and pressure values at that location. The coolant temperature at the engine outlet is a key parameter for ICE performance. Low coolant temperature results in a higher heat transfer between the engine cylinders and the coolant hence decrease the thermal efficiency of the ICE. Therefore, the coolant temperature of the ORC at the engine outlet $\left(\mathrm{T}_{1}\right)$ is respected to the one of the conventional cooling circuit. On the other hand, the evaporator outlet pressure $\left(\mathrm{P}_{1}\right)$ is varied between 1 to 16 bar to find full operating range of each fluid. The selection of the turbine operating point has a direct impact on the cycle performance. In order to maximize the turbine work output, the mass flow rate of the working fluid, the turbine pressure ratio and the inlet pressure and temperature must be push to the limits. The cycle mass flow rate is dictated by the fluid latent heat and the engine cooling requirements. The engine cooling requirements also fix the turbine inlet temperature. Hence, the only way to maximize the turbine power output is to maximize the turbine inlet pressure and the pressure ratio. Since the evaporator outlet temperature is fixed, there is an upper limit for the pressure which satisfies saturated/super-heated vapor conditions for the turbine inlet. When the pressure is too high, the engine excessive heat is not powerful enough to evaporate all the fluid amount. On the other hand, choice of pressure ratio is also critical. In one hand, the designers try to increase the expansion rate across to turbine to maximize the work output. However, above a certain threshold, the aerodynamics reduces the turbine efficiency resulting in a lower mechanical power output. The decision on the pressure ratio is given considering the calculated mass flow rate of the organic fluid and the turbine loading parameter. In the analysis, the turbine pressure ratio is kept as 2 which is a good compromise between the turbine efficiency and loading. Condensation is not allowed at the turbine outlet so the fluid phase at the turbine outlet is monitored for each run. The cases where the condensation occurs at the exit of the turbine are eliminated. Once the organic fluid is expanded in the turbine, it enters to the condenser unit. It is assumed that the condenser cools the fluid down to a temperature level which is $5 \mathrm{~K}$ lower than the boiling temperature. Finally, the working fluid is pumped back to the engine block. The evaporator, turbine, and the pump units are considered as non-isentropic elements so a constant efficiency value is taken into account for the thermodynamic analysis. Additionally, 5\% of pressure loss relative to the inlet condition is assumed in the condenser and evaporator components. Finally, all component specifications and the fluid conditions considered for the system performance analysis are listed in Table 2. 
Yasa / Anadolu Univ. J. of Sci. and Technology A-Appl. Sci. and Eng. 18 (3) - 2017

Table 2. ORC cycle parameters

\begin{tabular}{lcccc}
\hline & Evaporator & Turbine & Condenser & Pump \\
\hline Efficiency [\%] & 85 & 85 & N/A & 85 \\
Pressure Ratio (PR) $\left[\mathrm{P}_{\text {out }} / \mathrm{P}_{\text {in }}\right]$ & 0.95 & 0.5 & 0.95 & 2.22 \\
$\mathrm{~T}_{\text {out }}[\mathrm{K}]$ & 373 & Eq.5 & Eq.7 & Calc. \\
$\mathrm{P}_{\text {out }}[\mathrm{bar}]$ & $1-16$ & Eq. 1 & Eq.6 & Calc. \\
\hline
\end{tabular}

The thermodynamic properties of the working fluid are calculated by using an open source library, CoolProp [21]. CoolProp is a C++ library which contains pure and pseudo-pure fluid equations of state and transport properties for around hundred and twenty different fluids. The library provides fluid properties including pressure, temperature, enthalpy, specific heats (for both constant pressure and volume), etc. In order to reduce the design space, two criteria are considered for the fluids available in the library. The first of all, the fluid must be at least saturated vapor at the evaporator outlet conditions (Table 2). Secondly, the fluid is in fully liquid phase at the outlet of the condenser even for a hot day operation. Assuming an air temperature of $313 \mathrm{~K}$ for a hot day operation, the condensation outlet temperature is kept above to $318 \mathrm{~K}$ to have enough temperature difference between the air flow and the organic fluid. Finally, only nineteen fluids listed in Table 3 satisfying those two criteria are considered for the performance evaluation.

Table 3. The list of working fluid considered for final evaluation

\begin{tabular}{|c|c|c|c|c|c|c|c|}
\hline Fluid type & $\begin{array}{l}\mathrm{T}_{\text {sat }} \\
{[\mathrm{K}]}\end{array}$ & $\begin{array}{l}\mathrm{T}_{\mathrm{cr}} \\
{[\mathrm{K}]}\end{array}$ & $\begin{array}{c}\mathrm{C}_{\mathrm{p}}(\mathrm{liq} / \mathrm{vap}) \\
{[\mathrm{kJ} / \mathrm{kgK}]}\end{array}$ & $\begin{array}{c}\rho(\text { liq/vap) } \\
{\left[\mathrm{kg} / \mathrm{m}^{3}\right]}\end{array}$ & GWP100 & ODP & $\begin{array}{c}\text { Safety } \\
\text { Class } \\
{[22]}\end{array}$ \\
\hline Hexane & 341.4 & 507.8 & $2.4504-1.8988$ & $613.43-3.19$ & 3.1 & & \\
\hline Neopentane & 282.3 & 433.7 & $2.2171-1.6428$ & $601.55-3.22$ & N/A & & \\
\hline Isobutene & 265.8 & 418.1 & $2.2225-1.5375$ & $626.87-2.65$ & N/A & & \\
\hline Isohexane & 332.9 & 497.7 & $2.4092-1.8694$ & $615.48-3.27$ & N/A & & \\
\hline Isopentane & 300.6 & 460.4 & $2.2868-1.7110$ & $612.47-3.02$ & N/A & & \\
\hline Novec 649 & 321.8 & 441.8 & $1.1213-0.9001$ & $1528.2-12.61$ & 1 & 0 & \\
\hline R113 & 320.3 & 487.2 & $0.9400-0.6908$ & $1509.2-7.33$ & 6130 & 1 & A1 \\
\hline R114 & 276.4 & 418.8 & $0.9617-0.6773$ & $1519.1-7.73$ & 10000 & 1 & A1 \\
\hline R123 & 300.6 & 456.8 & $1.0226-0.6999$ & $1457.6-6.39$ & 77 & 0.02 & B1 \\
\hline R142b & 263.7 & 410.3 & $1.2318-0.8172$ & $1193.4-4.78$ & 2310 & 0.07 & $\mathrm{~A} 2$ \\
\hline $\mathrm{R} 245 \mathrm{fa}$ & 287.9 & 427.0 & $1.2929-0.8732$ & $1365.9-5.85$ & 1030 & 0 & B1 \\
\hline R236fa & 271.3 & 398.1 & $1.1929-0.8028$ & $1447.1-7.06$ & 9810 & 0 & A1 \\
\hline R236ea & 279.0 & 412.4 & $1.2333-0.8427$ & $1485.4-6.85$ & 1200 & 0 & N/A \\
\hline $\mathrm{R} 365 \mathrm{mfc}$ & 313.0 & 460.0 & $1.4071-1.0431$ & $1224.8-5.96$ & 794 & & A3 \\
\hline R600a & 261.1 & 407.8 & $2.2205-1.5446$ & $594.19-2.79$ & 4 & 0 & A3 \\
\hline R1234ze & 253.9 & 423.3 & $1.2815-0.8284$ & $1294.4-5.64$ & 6 & & $\mathrm{~A} 2$ \\
\hline RC318 & 266.9 & 388.4 & $1.0397-0.7442$ & $1615.3-9.42$ & 10300 & N/A & A1 \\
\hline Cis2Butene & 276.5 & 435.8 & $2.1576-1.4378$ & $640.46-2.54$ & N/A & N/A & \\
\hline Trans2Butene & 273.7 & 428.6 & $2.2210-1.5523$ & $626.83-2.57$ & N/A & N/A & \\
\hline
\end{tabular}

The performance analysis is started at the evaporator outlet since both temperature $\left(\mathrm{T}_{1}\right)$ and pressure $\left(\mathrm{P}_{1}\right)$ are known as they are the design choice. The turbine conditions are then calculated by using Eq. 15. Since the turbine outlet pressure is known, the condenser outlet pressure and corresponding boiling temperature of the working fluid are determined in order to compute the condenser outlet temperature and the rate of heat transfer (Eq. 6-8). Finally, the pump outlet conditions are computed in a similar way to the turbine by using Eq. 9-12. In all calculations, the specific heats $\left(\mathrm{c}_{\mathrm{p}, 12}, \mathrm{c}_{\mathrm{p}, 23}, \mathrm{c}_{\mathrm{p}, 34}\right)$ are defined as an average value between the inlet and outlet specific heats. Since, the fluid properties of all stations (1-4) 
are known, the mass flow rate of the working fluid is determined from the energy balance of the engine block. Finally, the overall performance of the ORC system is obtained by using Eq. 14 .

$$
\begin{array}{lc}
P_{2}=P_{1} * P R_{\text {turb }} & \text { Eq.1 } \\
T_{2, \text { isen }}=T_{1} *\left(P R_{\text {turb }}\right)^{\frac{\gamma}{\gamma-1}} & E q .2 \\
W_{\text {turb,isen }}=c_{p, 12} *\left(T_{1}-T_{2, \text { isen }}\right) & \text { Eq.3 } \\
W_{\text {turb }}=W_{\text {turb }, \text { isen }} * \eta_{\text {turb }} & \text { Eq.4 } \\
T_{2}=T_{1}-\frac{W_{\text {turb }}}{C_{p, 12}} & \text { Eq.5 } \\
P_{3}=P_{2} * P R_{\text {cond }} & \text { Eq.6 } \\
T_{3}=T_{\text {sat }, P_{2}}-5 & \text { Eq.7 } \\
Q_{\text {cond }}=c_{p, 23} *\left(T_{2}-T_{3}\right) & \text { Eq.8 } \\
P_{4}=P_{3} * P R_{\text {pump }} & \text { Eq. } 9 \\
W_{\text {pump }, \text { isen }}=v_{34} *\left(P_{3}-P_{4}\right) & \text { Eq.10 } \\
W_{\text {pump }}=\frac{W_{\text {pump }, \text { isen }}}{\eta_{\text {pump }}} & \text { Eq.11 } \\
T_{4}=T_{3}-\frac{W_{\text {pump }}}{C_{p, 34}} & \\
Q_{\text {ICE }}=m_{\text {ORC }} * c_{p, 41} *\left(T_{4}-T_{1}\right) & \text { Eq.12 } \\
\eta_{\text {ORC }}=\frac{W_{\text {turb }}-W_{\text {pump }}}{Q_{\text {ICE }}} & \text { Eq.13 }
\end{array}
$$

\section{RESULTS AND DISCUSSIONS}

The benefit of ORC application on diesel engine is analyzed first theoretically for a range of ORC efficiency between $0 \%$ and $16 \%$. As the first step, the ORC system efficiency is multiplied by the waste cooling heat to obtain ORC power. Then, the total mechanical power provided by the ICE is calculated by summing the ORC mechanical power and the ICE brake power. Finally, the total mechanical power is used to compute the overall engine performance $\left(\eta_{\text {ICE }}\right)$. The results of the analysis are listed in Table 4. The first condition where the ORC efficiency is $0 \%$ represents the conventional diesel engine without ORC adaptation (reference case). The benefit of ORC system adaptation is then computed relative to the reference case $\left(\Delta \eta_{\text {ICE }}\right)$. Based on the theoretical analysis, each $4 \%$ of ORC efficiency raises the engine performance by $1 \%$. 
Table 4. Effect of ORC on ICE overall performance

\begin{tabular}{|c|c|c|c|c|}
\hline ПоRC & $\begin{array}{c}\text { ORC Power Output } \\
{[\mathrm{kW}]}\end{array}$ & $\begin{array}{c}\text { ICE Brake Power } \\
{[\mathrm{kW}]}\end{array}$ & ПICE & $\Delta \eta_{\text {ICE }}$ \\
\hline $0 \%$ & 0 & 253 & $35.9 \%$ & --- \\
\hline $4 \%$ & 7 & 260.0 & $36.9 \%$ & $1.0 \%$ \\
\hline $8 \%$ & 14.1 & 267.1 & $37.9 \%$ & $2.0 \%$ \\
\hline $12 \%$ & 21.1 & 274.1 & $38.9 \%$ & $3.0 \%$ \\
\hline $16 \%$ & 28.2 & 281.2 & $39.9 \%$ & $4.0 \%$ \\
\hline
\end{tabular}

The operation pressure range of each fluid listed in Table 3 is reported in Figure 2. The turbine inlet condition dictates the upper pressure limit whereas the lower pressure limit is related to the temperature limit of the condensation operation. The results depicted in Figure 2 show that the working fluid can be grouped as high pressure fluids and low pressure fluids by using a line passing around 6 bar. The majority of available fluids operate at high pressures while only six fluids (isohexane, isopentane, Novec 649 , R113, R123 and R365mf) remains on the low pressure side.

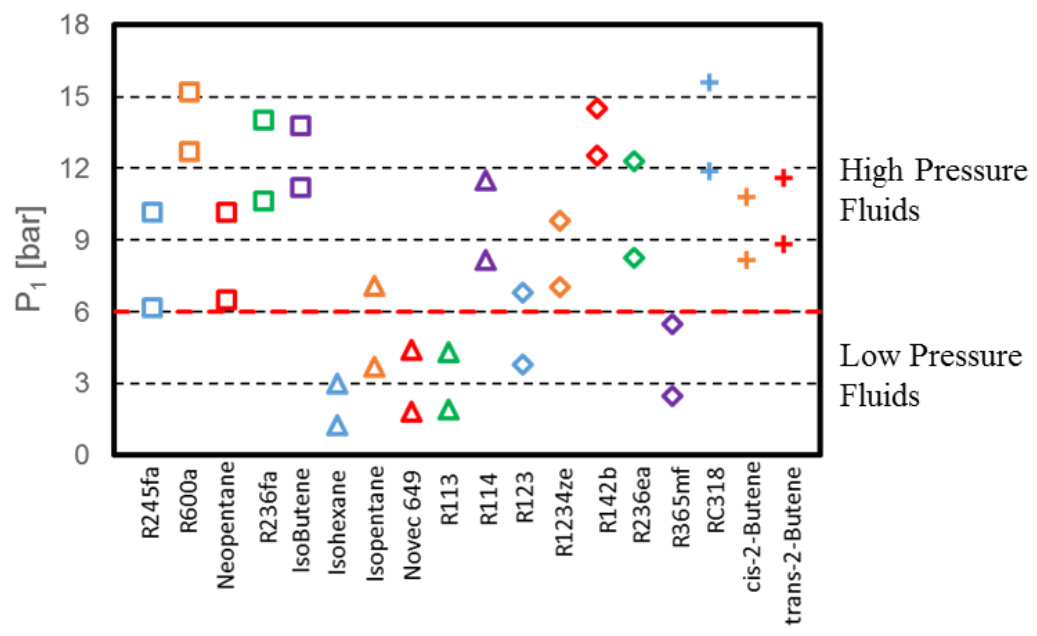

Figure 2. Operating ranges of the ORC working fluids

The relationship between the evaporator outlet pressure and the ORC thermal efficiency is plotted in Figure 3-a. The circle in the figure represents the efficiency of the ORC when it operates at the upper pressure limit of each fluid while triangles correspond to the operation of the system at lower pressure limits. The lines on Figure 3-a represent the linear fit of each data group therefore define an average operability limits and resultant system efficiencies. As expected, the higher operation pressure at the turbine inlet results in a better performance. The difference between the two operability lines increases for the higher operating pressure. In fact, it is an indication of the performance sensitivity to the fluid of choice. Therefore, the selection of working fluid becomes critical for higher operating pressure. The cases above the average operability line like RC318, R236fa point out the fluids that has superior performance. T-S diagram of candidate fluids are depicted also in Figure 3-b. Although higher operating pressure is good for the ORC performance, the selection of operating pressure influences the force acting on the system components. If the target for the safety margin of structural integrity and product lifetime are preserved, the operating pressure has a direct impact on the system weight. Therefore, a trade-off between the weight impact and the ORC efficiency must be considered carefully during the design. 


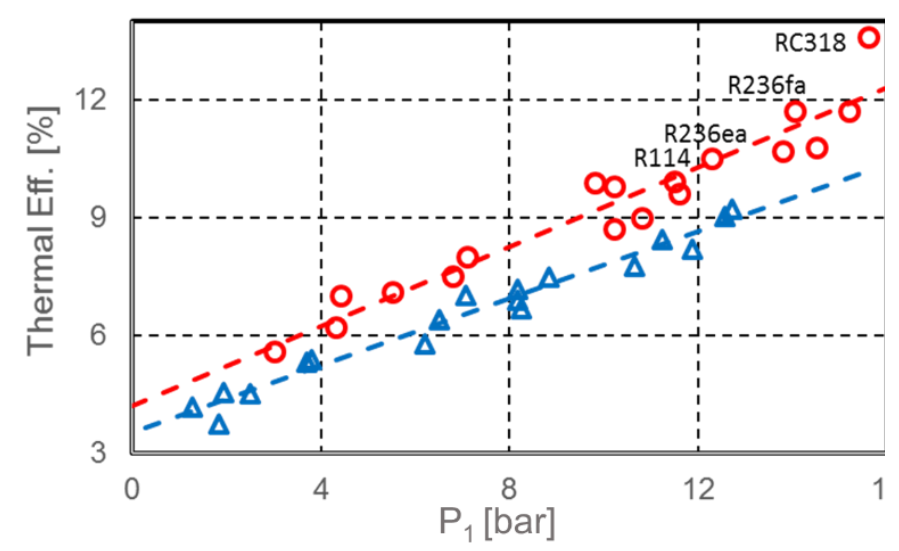

(a)

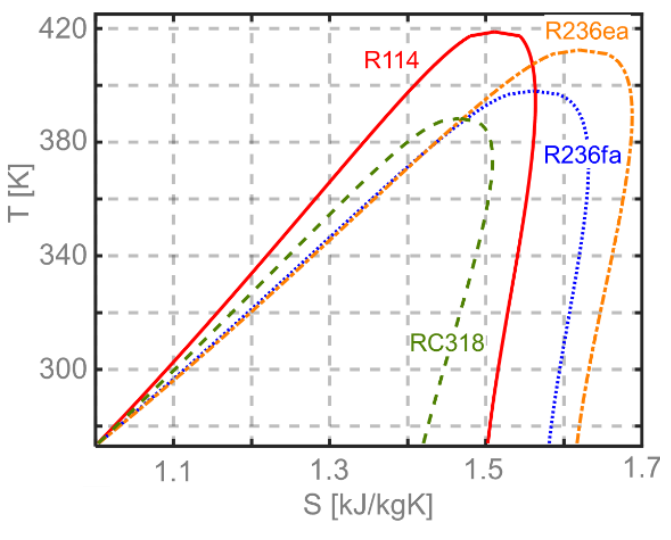

(b)

Figure 3. a) Variation of thermal efficiency by the evaporator outlet pressure b) T-S diagram of the candidate fluids
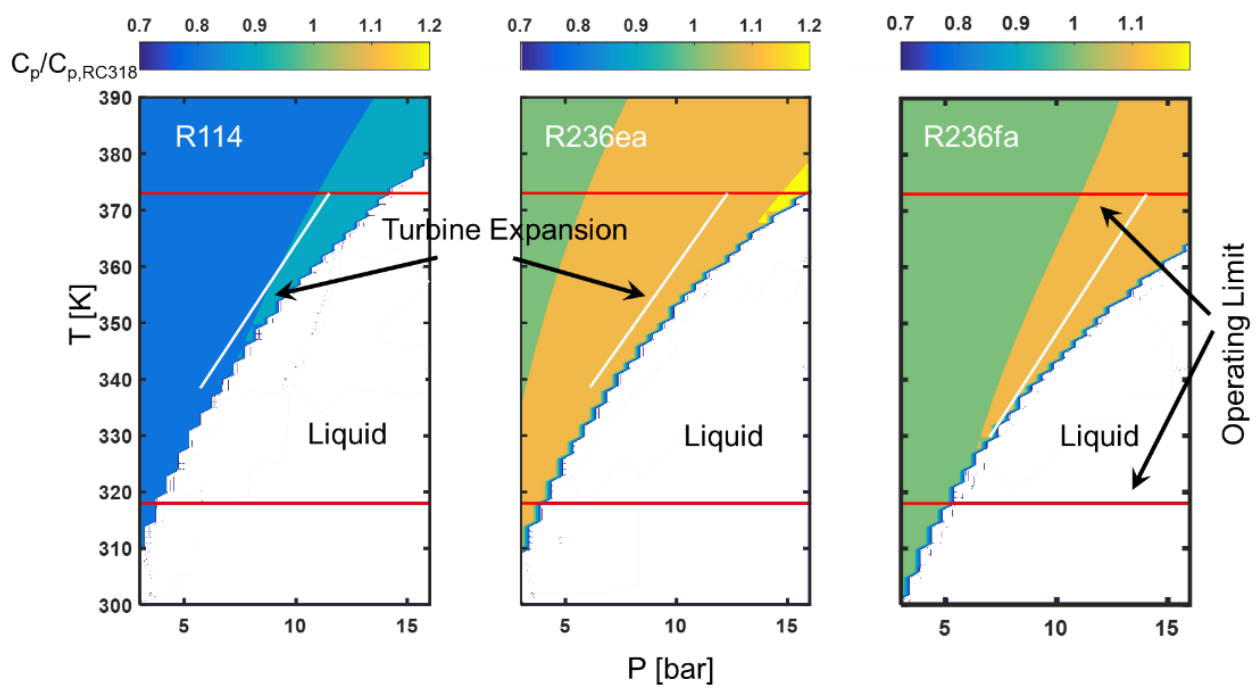

Figure 4. Comparison of the heat capacity ratio of R114, R236ea, R236fa

The heat capacity of a fluid is a critical parameter for turbine operations. Hence, the heat capacity ratio is computed by dividing the heat capacity of a given fluid to the heat capacity of RC318 at the same conditions. Figure 4 shows heat capacity ratio of R114, R236ea, R236fa. Beside the heat capacity, its variation across the turbine is also crucial for the cycle efficiency. Therefore, the expansion process of three fluids is plotted on top of the heat capacity ratio for the maximum possible inlet pressure. The heat capacity of R114 is always lower than the one of RC318 for all conditions. Therefore, for the same mass flow rate and the expansion ratio, ORC with $\mathrm{R} 114$ tends to produce less work output independently from the operating conditions. On the other hand, the heat capacity of R236ea and R236fa is higher than the one of RC318 therefore they have more work potential then the one of RC318. The analysis also confirm the statement. When the turbine inlet pressure is set to around 11 bar, the thermal efficiency of $7.7 \%$, $8.1 \%$, and $9.2 \%$ is obtained by the RC318, R236fa, and R236ea, respectively. However, the upper pressure limit of the RC318 is much higher than the others so it achieves better performance levels than the other because of its capability of operating high pressure levels. 
The mass flow rate of such system is another important parameter since it has an impact on sizing of the ORC components. Selection of proper mass flow rate is a compromise between the turbine and the heat exchanger designs. The low mass flow rate is preferable for the heat exchanger whereas it is not beneficial for the turbine since it results in a small airfoil size. The airfoils lower than two centimeters in height are difficult to design with high efficiency due to the manufacturing limitations. Therefore, a higher flow rate is the design choice to maximize the turbine efficiency and ease the turbine design. Figure 5 shows the variation of mass flow rate versus the efficiency of ORC system. Since a high mass flow rate and a high efficiency are design targets, the fluids close to the upper right corner are the most suitable candidates for the best ORC system. Based on the cycle analysis results, RC318 proves to provide the highest performance with a high level of mass flow rate which makes it a strong candidate for the working fluid. Following that, R236 family and R114 are listed as the alternative solutions.

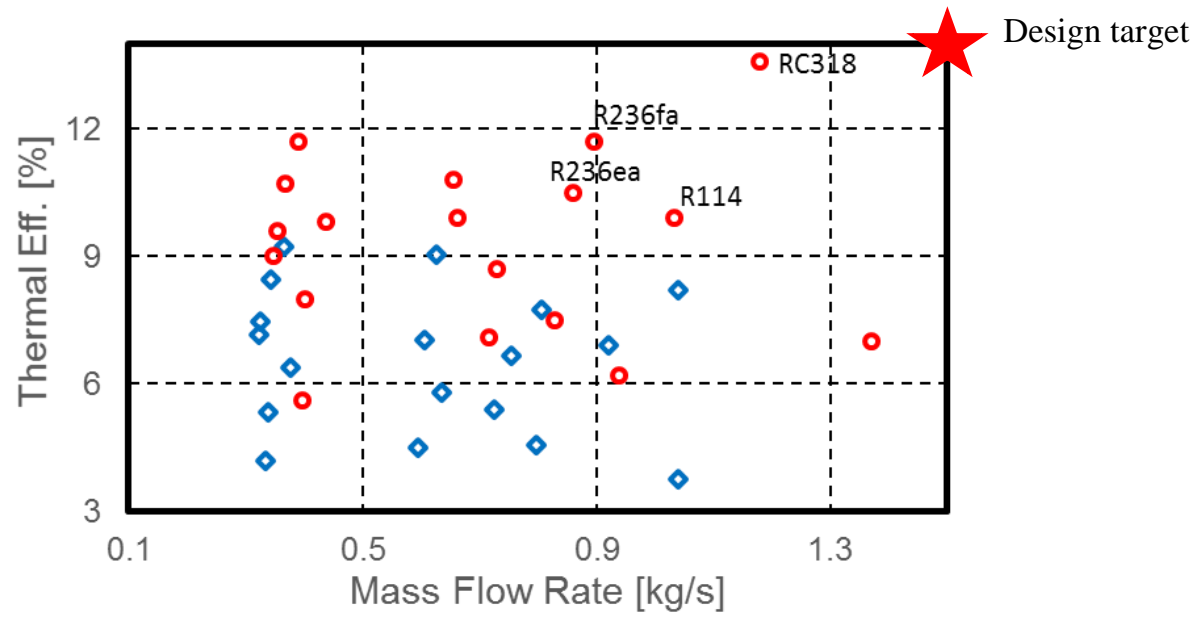

Figure 5. The relationship between the ORC efficiency and mass flow rate of different fluids

\section{CONCLUSION}

The diesel engines are the backbone of logistics and used daily bases over the worldwide. Therefore, the fuel efficiency of those systems has a great impact on sustainable energy consumption. Most of the fuel energy in the engines is wasted by the engine cooling and the exhaust gases spare a lot of room for the fuel economy by means of energy recovery systems. A heat recovery system replacing the current engine cooling system by an organic Rankine cycle is studied by cycle analysis. A heavy duty diesel engine used in trucks is considered as a test case and eighty working fluids are analyzed for the heat recovery system. The temperature of the working fluid at engine outlet is fixed at $100^{\circ} \mathrm{C}$ in order to respect the structural limits. Additionally, a temperature limit for the condensation is provided. Based on those limitations, the number of working fluids is reduced to 19 for cycle analysis. Then, the operating pressure range of each working fluid is investigated. Based on the analysis, the working fluids are split into two groups namely high pressure and low pressure fluids as taking the operating pressure of 6 bar as a limit. For low pressure fluids, the fluid selection does not have a significant impact on the performance whereas the fluid selection becomes a critical issue for high pressure fluids. The ORC system performance raises with the operating pressure. For each pressure level, an average efficiency line is provided based on linear fitting of the results data. Hence, fluids that provide better performance are easily distinguished from the others. The maximum efficiency of $13.6 \%$ is achieved when RC318 is used as the working fluid around 16 bar. In this case, the ORC system improves the diesel engine efficiency by around 3.5\%. Beside this particular case, $10 \%$ of efficiency for the ORC system proves to be reachable by most of the high pressure fluids like R600a, Neopentane, R236fa, R236ea, IsoButene, 
$\mathrm{R} 114, \mathrm{R} 142 \mathrm{~b}, \mathrm{RC} 318$. Beside the efficiency, the mass flow rate of the working fluid is taken into account for the cycle analysis since it has a direct effect on the sizing of the components especially in the turbine. The mass flow rate of each fluid is dictated by the waste heat amount of the engine and it is ranging between 0.3 and $1.2 \mathrm{~kg} / \mathrm{s}$ for the current test case. When high flow rate and high efficiency are selected as the design target, the best compromise is provided by the working fluid of RC318, R236 and R114. All three fluids provide an efficiency level above $10 \%$ with a mass flow rate of $0.8 \mathrm{~kg} / \mathrm{s}$. Such system means an enhancement of the diesel engine performance by $2.5 \%$ in terms of brake power efficiency.

\section{REFERENCES}

[1] Eurostat, 2015, Modal split of passenger transport, http://ec.europa.eu/eurostat/statisticsexplained/index.php/File:Modal_split_of_passenger_transport_2000-13.jpg

[2] Eurostat, 2016, Freight transport in the EU-28, http://ec.europa.eu/eurostat/statisticsexplained/index.php/File:Freight_transport_in_the_EU-28_(1)_modal_split_of_inland_transport_modes)_(\%25_of_total_tonne-km)new.png

[3] Edwards KD, Wagner RM, Briggs TE, Theiss TJ, 2011, Defining Engine Efficiency Limits, Presentations of $17^{\text {th }}$ Directions in Engine-Efficiency and Emissions Research, Detroit USA.

[4] Schuster A, Karellas S, Kakaras E, Spliethoff H. Energetic and economic investigation of organic Rankine cycle applications, Applied Thermal Engineering, vol. 29, 2009, pp.1809-1817.

[5] Yamamoto T, Furuhata T, Arai N, Mori K. Design and testing of the organic Rankine cycle, Energy, vol 26, 2001, pp. 239-251.

[6] Yang F, Zhang H, Bei C, Song S, Wang E. Parametric optimization and performance analysis of ORC (organic Rankine cycle) for diesel engine waste heat recovery with a fin-and-tube evaporator, Energy, vol. 91, 2015, pp.128-141.

[7] Yağlı H, Koç Y, Koç A, Görgülü A, Tandiroğlu A. Parametric optimization and exergetic analysis comparison of subcritical and supercritical organic Rankine cycle (ORC) for biogas fuelled combined heat and power (CHP) engine exhaust gas waste heat, Energy, vol. 111, 2016, pp. 923932.

[8] Chen Q, Xu J, Chen H A new design method for organic Rankine cycles with constraint of inlet and outlet heat carrier fluid temperatures coupling with the heat source, Applied Energy, Vol. 98, 2012, pp. 562-573.

[9] Maizza V, Maizza A. Unconventional working fluids in organic Rankine-cycles for waste energy recovery systems, Applied Thermal Engineering, Vol. 21, 2001, Pages 381-390.

[10] Wang EH, Zhang HG, Fan BY, Ouyang MG, Zhao Y, Mu QH. Study of working fluid selection of organic Rankine cycle (ORC) for engine waste heat recovery, Energy, vol.36, 2011, pp. 3406-3418.

[11] Tian H, Shu GQ, Wei HQ, Liang XY, Liu LN. Fluids and parameters optimization for the organic Rankine cycles (ORCs) used in exhaust heat recovery of internal combustion engine (ICE), Energy, vol.47, 2012, pp. 125-136.

[12] Di Battista D, Cipollone R., Villante C, Fornari C, Mauriello M. "The Potential of Mixtures of Pure Fluids in ORC-based Power Units fed by Exhaust Gases in Internal Combustion", Energy Procedia, vol. 101, 2016, pp. 1264-1271. 
[13] Wang TY, Zhang YJ., Zhang J, Peng ZJ, Shu GQ. Comparisons of system benefits and thermoeconomics for exhaust energy recovery applied on a heavy-duty diesel engine and a light-duty vehicle gasoline engine. Energy Conversion and Management, vol. 842014, pp. 97-107.

[14] Zhao M, Wei M, Song P, Liu Z, Tian G. Performance evaluation of a diesel engine integrated with ORC system. Applied Thermal Engineering, Vol. 115, 2017, pp. 221-228.

[15] Badescu V, Aboaltabooq MHK, Pop H, Apostol V, Prisecaru M, Prisecaru T, 2017. Design and operational procedures for ORC-based systems coupled with internal combustion engines driving electrical generators at full and partial load. Energy Conversion and Management, vol. 139, pp. 206221.

[16] Yu G, Shu G, Tian H, Wei H, Liu L. Simulation and thermodynamic analysis of a bottoming Organic Rankine Cycle(ORC) of diesel engine (DE). Energy vol. 51, 2013, pp.281-290.

[17] Keçeci A, Türkiye'de Karayolu Taşımacılığı, Uluslararası Ekonomik Sorunlar Dergisi Vol. XX, T.C. Dışişleri Bakanlığı Yayınları. 2006,

[18] Abedin MJ, Masjuki HH, Kalam MA, Sanjid A, and Rahman SMA. Thermal Balancing of a MultiCylinder Diesel Engine Operating on Diesel, B5 and Palm Biodiesel Blends. Journal of Clean Energy Technologies, Vol. 3, No. 2, 2015, pp.115-118.

[19] Desai SJ, Shivkumar S. Heat Balance Sheet of Single Cylinder Diesel Engine by Introducing Oxygen in the Air Intake, International Research Journal of Engineering and Technology, Vol. 2, Issue 8, 2015, pp. 183-189.

[20] Tauzia X, Maiboom A. Experimental study of an automotive Diesel engine efficiency when running under stoichiometric conditions, Applied Energy, Vol. 105, 2013, pp. 116-124.

[21] Bell IH, Wronski J, Quoilin S, Lemort V. Pure and Pseudo-pure Fluid Thermophysical Property Evaluation and the Open-Source Thermophysical Property Library CoolProp, Industrial \& Engineering Chemistry Research, vol. 53, issue 6, 2014, pp. 2498 - 2508.

[22] ASHRAE Standard, 2008, Designation and Safety Classification of Refrigerants, ANSI/ASHRAE Standard 34-2007, ISSN 1041-2336 